\title{
The effects of weekly motivational phone calls on the amount of leisure sports activities and changes in physical fitness
}

\author{
Badicu G. ${ }^{1 \mathrm{ABCDE}}$, Gatterer H. ${ }^{2 \mathrm{ABCDE}}$, Balint L. ${ }^{1 \mathrm{ABCDE}}$, Burtscher M. ${ }^{3 \mathrm{ABCDE}}$ \\ ${ }^{1}$ Department of Physical Education and Special Motility, Faculty of Physical Education and Mountain Sports, \\ University Transilvania of Braşov, Romania \\ ${ }^{2}$ Institute of Mountain Emergency Medicine, EURAC Research, Bolzano, Italy \\ ${ }^{3}$ Department of Sport Science, Sports Medicine and Prevention, University of Innsbruck, Austria
}

Authors' Contribution: A - Study design; B - Data collection; C - Statistical analysis; D - Manuscript Preparation; E - Funds Collection.

\begin{abstract}
Purpose: $\quad$ The purpose of this study is to investigate whether motivational weekly phone calls are able to promote overall and/or leisure physical activity levels and fitness in an urban population of Romania.

Material: $\quad$ Sixty-five adult subjects (30 males and 35 females) were randomly selected and followed over the 8-month study period. Total physical activity and changes in body mass and body mass index $\left(\mathrm{kg} / \mathrm{m}^{2}\right)$ were recorded on a monthly basis. Fitness level was assessed by the participants themselves using three standardized motor tests: push-up test, 1-minute sit-up test and 3-minute step test.

Results: $\quad$ The intervention resulted in an increase of physical activity level by approximately $70 \%$ in males and females aged $25-39$ years. In those aged $40-49$ years physical activity levels were enhanced by $77 \%$ in males and $18 \%$ in females. These changes were associated with improvements $(25-31 \% ; p<0.01)$ in fitness levels. Changes in physical activity over the 8-month intervention period were negatively correlated with body mass index ( $r$ $=-0.721, \mathrm{p}<0.01$.

Conclusions: This study demonstrates that motivation by regular phone calls was highly effective in increasing leisure sports activities and improving fitness levels in young and middle-aged adults of both sexes.

Keywords: leisure sports activities, physical fitness, adults, physical activity, body mass index, phone calls.
\end{abstract}

\section{Introduction}

The importance of regular physical activity (PA) is generally recognized in the prevention of many chronic diseases, such as diabetes, cardiovascular diseases and some cancers [1-3]. Additionally, adequate PA and leisure sports activity improves physical performance, selfconfidence and physical and psychological independence [4] and contributes to 'quality of life', which comprises perceived global satisfaction and well-being [5]. Physical and leisure sports activities can favor various areas of well-being, such as physical, psychical as well as social well-being [6]. With respect to physical well-being, the type and intensity of physical or sport activity determines the way the human body adapts. Also, frequency and volume of PA are at least equally important. PA at a moderate intensity and engaging large muscle mass (e.g. walking) leads to general adaptations enabling the individual to better cope with the usual challenges of life (e.g. walking tasks, stair climbing) [7]. In contrast, if the goal is to improve physical fitness, sports activities performed at higher intensity are needed; these include, for example, running, jogging, swimming, cycling and aerobic gymnastics [8, 9].

From a health perspective, the World Health Organization (2017) $[10,11]$ recommends at least 150 minutes of moderate-intensity, or at least 75 minutes of vigorous-intensity aerobic exercise throughout the week or an equivalent combination of moderate and vigorous-intensity activity. The aerobic activity should be performed in bouts of at least 10 minutes duration. For

(c) Badicu G., Gatterer H., Balint L., Burtscher M., 2018

doi:10.15561/18189172.2018.0501 additional health benefits, adults are even encouraged to increase their moderate-intensity aerobic activity to 300 minutes per week, or engage in 150 minutes of vigorousintensity aerobic exercise per week. Moreover, musclestrengthening activities should be included involving major muscle groups on 2 or more days a week. As it is essential for PA to be undertaken on a regular basis for sustained improvements in health, ensuring that individuals are participating in activities that are a source of happiness and satisfaction is important for long-term adherence [12].

However, developing positive attitudes toward activity or sport is often a challenging task and strategies helping to overcome personal constraints are needed. Professional and regular counseling might be one strategy to start with. Such approaches, among others, include face-toface exercise or behavioral/cognitive consultation, or motivational phone calls promoting physical and leisure sports activities [2, 13, 14]. With professional support and repeated contacts, which seem to be important for behavioral changes [8], people might overcome initial inhibitions, start being active or increase their activity level and continue to be active on a regular basis as they experience the benefits of being so (e.g. improved fitness level, health status) [15].

The evidence of regular phone calls to promote physical and/or leisure sports activities is strong, yet the optimal intervention dose (e.g., duration and frequency of telephone contacts) $[2,14]$ and the effect of the increased PA on physical performance has not yet been well studied. Thus, this study aimed to investigate whether weekly motivational phone calls for 8 months were able 
to promote physical and/or leisure sports activities and to increase physical fitness in people aged between 25 and 49 years. We hypothesized that with weekly phone calls the physical and/or leisure sports activity level can be increased and that the individual level of physical fitness is related to active participation in leisure sports activities.

\section{Material and methods}

Participants: Overall, 500 adults (229 men and 271 women) aged between 25 and 49 years were randomly selected at different locations (in the region of Braşov, Romania) and were asked to voluntarily participate in the survey. Of these, 318 (149 men and 169 women) subjects were contacted during or after practising organized and non-organized leisure sports activities at different sports facilities (e.g. track and field facility, running trails) and 182 participants (81 men and 101 women) were randomly selected on the streets of Braşov. All subjects were handed out a questionnaire focusing on physical health and participation in leisure sports activities. The participants had to indicate how often they practised leisure sports per week (i.e. less than 1 hour, 1-2 hours, 3-4 hours, 5-6 hours) and only participants practising sports for 1 hour and 1-2 hours were included for further participation as we intended to investigate the effects of increasing leisure sports activities. Finally, 65 adults (30 men and 35 women) were included and these were split into two age categories: (1) 25-39 yrs ( $\mathrm{N}=27,12$ males and 15 females); (2) 40-49 yrs ( $\mathrm{N}=38,18$ males and 20 females). Of the 65 selected adults, 20 (10 men and 10 women) have been recruited on the street and the remaining 45 (20 men and 25 women), have been recruited after practicing sport. Baseline characteristics of the participants are shown in Table 1.

Table 1. Baseline characteristics of participants

\begin{tabular}{ll}
\hline Variable & Mean (SD) \\
$\mathbf{N}=\mathbf{6 5}$
\end{tabular}

Organization of the research: The study period lasted for 8 months, from April 2013 to November 2013. During this time period participants were handed training logs and asked to daily record the type (what sport activities were attended: walking, running, hiking, fitness etc) and duration (in minutes) of their leisure time activities as well as their actual body weight. Everyday activities such as household, gardening and occupational activities were not questioned. Additionally, every month the participants performed a physical fitness test at home, as outlined in detail below.

After their engagement, participants were called by phone every week to motivate them to practice sport and additionally they received weekly information on all sports activities (e.g. guided classes, sport events) where they could additionally participate during the course of the study. During the weekly phone calls participants were also asked to send their records via e-mail which they followed reliably. Phone calls were done always by the same researcher experienced in motivational phone calls, i.e., B.G.

The training logs were used to calculate the total PA over the 8-month study period as well as to establish changes in body weight and body mass index (BMI) (kg/ $\mathrm{m}^{2}$ ). The fitness level was assessed by the participants themselves, with three standardized, simple and easy accessible motor tests [16]. The participants were advised/ trained to correctly perform the test through written instructions and by video [16] sent via e-mail.

The motor tests were designed to evaluate muscle strength (dynamic) of the upper limbs and the abdominal muscles as well as endurance performance. The first test was a push-up test. After receiving the video, participants were given the following instructions: 'Men should use the standard "military style" push-up position with only the hands and the toes touching the floor in the starting position. Women have the additional option of using the "bent knee" position. To do this, kneel on the floor, hands on either side of the chest and keep your back straight.

Lower the chest down towards the floor, always to the same level each time, either till your elbows are at right angles or your chest touches the ground. Do as many push-ups as possible until exhaustion. Count the total number of push-ups performed [16].

Women were given the option for the simpler test as it was assumed that not every woman would be able to perform the test in its original form.

The second test was a 1-minute sit-up test with the following instructions given to the participants. 'Lie on a carpeted or cushioned floor with your knees bent at approximately right angles, with feet flat on the ground. Your hands should be resting on your thighs. Squeeze your stomach, push your back flat and raise high enough for your hands to slide along your thighs to touch the tops of your knees. Don't pull with you neck or head and keep your lower back on the floor. Then return to the starting position. Count how many you can do in one minute [16].

The endurance performance was assessed by a 3-minute step test. The following instructions were given to the participants: 'Step on and off the box $(30.5 \mathrm{~cm})$ for 3 minutes. Step up with one foot and then the other. Step down with one foot followed by the other foot. Try to maintain a steady four beat cycle. It's easy to maintain if you say "up, up, down, down". Go at a steady and consistent pace. At the end of 3 minutes, remain standing while you immediately check your heart rate. Take your pulse for 1 minute (e.g. count the total beats from 3 to 4 minutes after starting the test) [16].

The outcomes of the tests have been rated according to tables presented on the site [16]. For the purpose of analysis the rating for each test has been replaced by numerical numbers (scores) as follows: very weak - score 4; weak - score 5; below average - score 6; average 
- score 7; above average - score 8; good - score 9; excellent - score 10. A rating of 30 indicates overall excellent physical fitness and a rating of 12 overall very weak physical fitness for the three motor tests.

Statistical analyses: Statistical analyses were conducted by SPSS (IBM Corp. Released 2013. IBM SPSS Statistics for Windows, Version 22.0. Armonk, NY: IBM Corp.). Data are presented as means (SD). Normal distribution of data was confirmed by using Kolmogorov Smirnov test. Paired t-tests were used to evaluate changes from pre to post 8 months of intervention. Correlation analyses (Pearson) were used to evaluate the relationship between variables (fitness levels and BMI). A P-value < 0.05-was considered to indicate statistical significance.

\section{Results}

Changes in PA, fitness level and body composition in the course of the 8 months intervention period are shown for the two age groups in Table 2. The intervention resulted in a self-reported increase in PA by about $70 \%$ in males and females of the younger age group (25-39 years). In the 40-49 years age group, males increased their PA level by $77 \%$, whereas females increased it by only $18 \%$. For the $25-39$ years age group, the number of sport activities practiced per week increased from 1.6 to 2.7 in males $(\mathrm{N}=12)$, and from 1.5 to 3.2 in females $(\mathrm{N}$ $=15$ ). For the 40-49 years age group, the total number increased from 1.3 to 2.3 in men $(\mathrm{N}=18)$, and from 1.4 to 3.2 in women $(\mathrm{N}=20)$.

After the intervention, the general fitness levels were increased by $25-31 \%$ in males and females of both age groups. Prior to the intervention, BMI was slightly elevated in both sexes of the younger age group and in middle-aged males. Increased PA over the 8-month intervention period was associated with a decrease in BMI by about $15 \%$ in the groups with elevated BMI and by $5 \%$ in middle-aged females with an already normal BMI at the beginning of the study. Changes in PA over the 8-month intervention period were positively correlated with changes in fitness levels $(\mathrm{r}=0.835, \mathrm{p}<0.01)$ and negatively with BMI $(\mathrm{r}=$ $-0.721, \mathrm{p}<0-01)$.

\section{Discussions}

The main findings of this study are: (1) that motivation by phone calls in addition to providing information on sport events and facilities, was highly effective in increasing leisure sport activities in males and females aged 25-49 years and (2) that changes in the amount of leisure sports activities were closely and positively correlated with individual changes in fitness levels and negatively with BMI.

Numerous lifestyle intervention studies investigated the effects of motivational phone calls as well as individual counseling in addition to offering out-of-hospital exercise courses on health outcomes and PA levels [2, 17-19].

Studies reported that telephone intervention may indeed be effective in increasing PA $[2,14]$. However, it was also found that well-organized hospital-based exercise programs compared to a home-based training intervention are more effective in improving exercise capacity in patients with heart disease and type 2 diabetes or in patients undergoing heart transplant $[20,21]$. In addition, Burtscher et al. (2009) [22] found that in contrast to a non-supervised training programs with only one counseling session, which was not effective in improving physical fitness, weekly advice together with supervised exercise increased adherence, and more importantly also fitness. Present data show that weekly counseling alone, without supervised exercise, is also capable of improving adherence and, as a consequence, physical fitness.

The present findings are in accordance with Philippaerts et al. (1999) [23], who also showed that

Table 2. Amount of leisure sports activity, fitness level and body mass index (BMI) pre and post 8 months of intervention

\begin{tabular}{|c|c|c|c|c|}
\hline \multirow{4}{*}{ Variable } & \multicolumn{4}{|l|}{ Age Group } \\
\hline & \multicolumn{2}{|l|}{ 25-39 } & \multicolumn{2}{|l|}{$40-49$} \\
\hline & $\begin{array}{l}\text { Male F } \\
\text { Mean (SD) }\end{array}$ & Female & $\begin{array}{l}\text { Male } \\
\text { Mean (SD) }\end{array}$ & Female \\
\hline & $\mathrm{N}=12$ & $\mathbf{N}=\mathbf{1 5}$ & $\mathrm{N}=18$ & $\mathbf{N}=\mathbf{2 0}$ \\
\hline BMI pre $\left(\mathrm{kg} / \mathrm{m}^{2}\right)$ & $25.37 \pm 3.02$ & $25.1 \pm 4.05$ & $27.33 \pm 3.4$ & $23.05 \pm 2.7$ \\
\hline BMI post $\left(\mathrm{kg} / \mathrm{m}^{2}\right)$ & $22.57 * \pm 2.2$ & $21.86^{*} \pm 2.6$ & $23.9^{*} \pm 2.5$ & $21.9 * \pm 2.4$ \\
\hline $\begin{array}{l}\text { Total PA pre (total number of sports activities per } \\
\text { week) }\end{array}$ & $1.6 \pm 0.7$ & $1.5 \pm 0.6$ & $1.3 \pm 0.8$ & $1.4 \pm 0.7$ \\
\hline $\begin{array}{l}\text { Total PA post (total number of sports activities per } \\
\text { week) }\end{array}$ & $2.7^{*} \pm 0.9$ & $3.2 \pm 1.5$ & $2.3^{*} \pm 1.2$ & $3.2 * \pm 1.5$ \\
\hline Fitness pre ( 3 motoric tests- summary score) & $14.1 \pm 1.2$ & $13.8 \pm 1.3$ & $13.8 \pm 1.1$ & $13.3 \pm 1.1$ \\
\hline Fitness post ( 3 motoric tests - summary score) & $28.5 * \pm 2.2$ & $27.8 \pm 2.8$ & $27.2 * \pm 2.7$ & $26.9 * \pm 2.9$ \\
\hline
\end{tabular}

* indicate significant changes from pre to post; all $p$ values $<0.01$.

$\mathrm{PA}=$ physical activity $; \mathrm{BMI}=$ Body mass index . 
there is a relationship between PA during work and leisure time and several components of physical fitness. Additionally, Philippaerts et al. found that PA during work was modestly, but inversely related to adiposity. From a health perspective, increasing physical fitness and reducing adipose tissue is important as physical fitness and overweight are considered independent predictors of several cardiovascular diseases, diabetes mellitus and allcause mortality [24-27]. Thus, the present results indicate that weekly counseling might be one preventive measure to improve health in the general population and hence to also reduce health-care-related costs [25].

Some limitations of the present study have to be mentioned. Our findings are certainly limited by the relatively small sample size and the uncontrolled nature of the study design. Additionally, the self-assessment of physical fitness and PA level might have led to some inaccuracies. Nonetheless, due to the personal and weekly contact with the participants, allowing the buildup of a trustful relationship with the awareness that only true data are the basis for good science, we are confident that the participants honestly reported their PA and performance level.

\section{Conclusions}

The presented findings demonstrate that weekly motivation by phone calls in addition to providing information on sport events and facilities was highly effective in increasing leisure sports activities in both sexes of both young and middle-aged adults. Importantly, changes in the amount of leisure sports activities were closely and positively correlated with individual changes in fitness level and negatively with BMI. Therefore, implementation of the outlined practice may be recommended in order to improve performance capacity and health. However, if this implementation is able to reduce health costs cannot be appraised from this study and should be the focus of further investigations.

\section{Conflict of interests}

The authors declare that there is no conflict of interest.

\section{References}

1. World Health Organization. Global Strategy on Diet, Physical Activity and Health Physical Activity and Adults. [Internet] 2018 Jan 2 [updated 2018 Jan 10; cited 2018 Jan 31]. Available from: http://www.who.int/dietphysicalactivity/ factsheet_adults/en/

2. Eakin EG, Lawler SP, Vandelanotte C, Owen N. Telephone interventions for physical activity and dietary behavior change: a systematic review. American Journal of Preventive Medicine, 2007; 32(5):419-34. doi:10.1016/j. amepre.2007.01.004

3. Eyre H, Kahn R, Robertson RM, American Cancer Society, the American Diabetes Association and American Heart Association. Collaborative Writing Committee. Preventing cancer, cardiovascular disease, and diabetes: a common agenda for the American Cancer Society, the American Diabetes Association, and the American Heart Association. Diabetes Care, 2004; 27(7):1812-24. doi:10.2337/ diacare.27.7.1812

4. Gislaine V, Valter CB, Natália BM, Valdomiro de O, Oldemar M, Wagner de C. Association between physical activity and quality of life in the elderly: a systematic review, 2000 2012. Revista Brasileira Psiquiatria, 2014; 36(1):76-88. doi:10.1590/1516-4446-2012-0895

5. Hőrnquist J.O. Quality of life: concept and assessment. Scandinavian Journal of Social Medicine, 1990; 18(1): 69-79.

6. Tudor ID, Tudor M. Leisure Sports Activities Impact on Adults Personal Development and Quality of Life. Procedia - Social and Behavioral Sciences, 2013; 84:1090-1094. doi:10.1016/j.sbspro.2013.06.705

7. Brown M, Sinacore DR, Host HH. The relationship of strength to function in the order adult. Journal of Gerontology, $50 A, 1995 ; 50: 113-119$. doi:10.1093/gerona/50A.Special_ Issue. 55

8. Kenneth H. Notes on Physical Fitness. Institute for Aerobics research, Dallas; 2011.

9. Jagiełło W, Jagiełło M, Kalina RM, Barczynski BJ, Litwiniuk A, Klimczak J. Properties of body composition of female representatives of the Polish national fencing team - the sabre event. Biology of Sport 2017;34:401-6. doi:10.5114/ biolsport.2017.70526

10.Global Recommendations on Physical Activity For Health, World Health Organization. [Internet] 2018 Jan 2 [updated 2018 Jan 10; cited 2018 Jan 31]. Available from: http://apps. who.int/iris/bitstream/10665/44399/1/9789241599979_eng. pdf

11. World Health Organization Romania Physical Activity Factsheet. Monitoring and surveillance. [Internet] 2018 Jan 2 [updated 2018 Jan 10; cited 2018 Jan 31]. Available from: http://www.euro.who.int/_data/assets/pdf_ file/0005/288122/ROMANIA-Physical-Activity-Factsheet. pdf?ua

12.Epuran M. Motricity and psychism in bodily activities. FEST Bucharest Publish House; 2011. (in Romanian)

13.Alothman S, Yahya A, Rucker J, Kluding PM. Effectiveness of interventions for promoting objectively measured physical activity of adults with type 2 diabetes: a systematic review. Journal of Physical Activity and Health, 2017; 14(5):1-25. doi:10.1123/jpah.2016-0528

14.Goode AD, Reeves MM, Eakin E.G. Telephone-delivered interventions for physical activity and dietary behavior change: an updated systematic review. American Journal of Preventive Medicine, 2012; 42(1):81-8.doi:10.1016/j. amepre.2011.08.025

15.Niculescu M, Georgescu L, Marinescu A. Physical conditions and health. Publish House Universitaria; 2006. (in Romanian)

16.Canadian Public Health Association Project, Fitness Testing at Home - Cheap and Easy. [Internet] 2018 Jan 2 [updated 2018 Jan 10; cited 2018 Jan 31]. Available from: http://www. topendsports.com/testing/tests/home-step.htm

17.Tuomilehto J, Lindstrom J, Eriksson JG. et al. Prevention of type 2 diabetes mellitus by changes in lifestyle among subjects with impaired glucose tolerance. The New England Journal of Medicine, 2001; 344(18): 1343-50. doi:10.1056/ NEJM200105033441801

18.Mensink M, Blaak EE, Wagenmakers AJ. et al. Lifestyle intervention and fatty acid metabolism in glucose-intolerant subjects. Obesity Research, 2005; 13(8):1354-1362. 
doi:10.1038/oby.2005.164

19.Diabetes Prevention Program Study Group. Reduction in the incidence of type 2 diabetes with lifestyle intervention or metformin. The New England Journal of Medicine, 2002; 346:393-403.

20.Soja A.M, Zwisler AD, Frederiksen M. et al. Use of intensified comprehensive cardiac rehabilitation to improve risk factor control in patients with type 2 diabetes mellitus or impaired glucose tolerance: the randomized Danish Study of impaired glucose metabolism in the settings of cardiac rehabilitation (DANSUK) study. American Heart Journal, 2007; 153(4):621-628. doi:10.1016/j.ahj.2007.01.030

21.Karapolat H, Eyigor S, Zoghi M. et al. Comparison of hospital-supervised exercise versus home-based exercise in patients after orthotopic heart transplantation: effects on functional capacity, quality of life, and psychological symptoms. Transplantation Proceedings, 2007; 39(5), 15868. doi:10.1016/j.transproceed.2007.01.079

22.Burtscher M, Gatterer H, Kuncziky H, Brendstätter E, Ulmer H. Supervised exercise in patients with impaired fasting glucose: impact on exercise capacity. Clinical Journal of Sport Medicine, 2009; 19:394-398. doi:10.1097/
JSM.0b013e3181b8b6dc

23.Philippaerts RM, Lefevre J, Delvaux K, Thomis M, Vanreusel B, Vanden EB, Claessens AL, Lysens R, Beuneng G. Associations between daily physical activity and physical fitness in Flemish males: a cross-sectional analysis, American Journal of Human Biology, 1999; 11:587-597. doi:10.1002/ (SICI) $1520-6300$

24.Myers J, Prakash M, Froelicher V, Do D, Partington S, Atwood JE. Exercise capacity and mortality among men referred for exercise testing. The New England Journal of Medicine, 2002; 346:793-801. doi:10.1056/NEJMoa011858

25.Bomberg E, Birch L, Endenburg N, German AJ, Neilson J, Seligman H, Takashima G, Daz MJ. The financial costs, behavior and psychology of obesity: a one health analysis. Journal of Comparative Pathology, 2017;156:310-325. doi:10.1016/j.jcpa.2017.03.007

26.Gatterer H, Ulmer H, Dzien A, Somavilla M, Burtscher M. High cardiorespiratory fitness is more beneficial in prediabetic men than women. Clinics, 2011; 66(5):747-51. doi:10.1590/S1807-59322011000500007

27.Bădău D, Prebeg G, Mitić D, Bădău A. Fitness index and $\mathrm{VO}_{2 \max }$ of physical education students. Science, Movement and Health, 2015; 15(2):246--251.

\section{Information about the authors:}

Badicu G.; (Corresponding author); http://orcid.org/0000-0003-4100-8765; georgian.badicu@unitbv.ro; Department of Physical Education and Special Motility, Faculty of Physical Education and Mountain Sports, University Transilvania of Braşov; Bulevardul Eroilor 29, Brașov 500036, Romania.

Gatterer H.; http://orcid.org/0000-0002-5084-2930; georgian.badicu@unitbv.ro; Institute of Mountain Emergency Medicine of EURAC Research; Viale Druso, 1 / Drususallee 1, 39100 Bolzano / Bozen, Italy.

Balint L.; http://orcid.org/0000-0003-3503-6233; georgian.badicu@unitbv.ro; Department of Physical Education and Special Motility, Faculty of Physical Education and Mountain Sports, University Transilvania of Braşov; Bulevardul Eroilor 29, Brașov 500036, Romania.

Burtscher M.; http://orcid.org/0000-0002-5232-3632; georgian.badicu@unitbv.ro; University of Innsbruck, Department of Sport Science, Sports Medicine and Prevention; Fürstenweg 185, A-6020, Innsbruck, Austria.

Cite this article as: Badicu G, Gatterer H, Balint L, Burtscher M. The effects of weekly motivational phone calls on the amount of leisure sports activities and changes in physical fitness. Pedagogics, psychology, medical-biological problems of physical training and sports, 2018;22(5):226-230. doi:10.15561/18189172.2018.0501

The electronic version of this article is the complete one and can be found online at: http://www.sportpedagogy.org.ua/index.php/PPS/issue/archive

This is an Open Access article distributed under the terms of the Creative Commons Attribution License, which permits unrestricted use, distribution, and reproduction in any medium, provided the original work is properly cited (http://creativecommons.org/licenses/by/4.0/deed.en).

Received: 06.02.2018

Accepted: 10.03.2018; Published: 30.09.2018 